\title{
Effect of the solar dehydration on the antioxidant capacity and the content of flavonoids of the blackberry pulp (rubus spp)
}

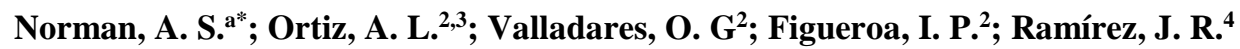 \\ ${ }^{a}$ Posgrado en Ciencias de la Sostenibilidad. Universidad Nacional Autónoma de México \\ b Instituto de Energías Renovables. Universidad Nacional Autónoma de México, Morelos, México \\ ${ }^{\mathrm{c}}$ Consejo Nacional de Ciencia y Tecnología. Ciudad de México \\ ${ }^{\mathrm{d}}$ Instituto Politécnico Nacional, Centro Interdisciplinario de Investigación para el Desarrollo Integral \\ Regional (CIIDIR) Unidad Oaxaca
}

* E-mail of the corresponding author: azucenanorman@gmail.com

\begin{abstract}
Technical performance of two solar drying technologies was evaluated: Solar Greenhouse Drying (SGD) with auxiliary heating system, and Direct Solar Drying (DSD) in order to evaluate its effect on antioxidant activity (AA) and total flavonoids of blackberry (rubus spp) waste destined. The SDG and DSD results were compared with those of the dehydrated samples in an electric stove (ES). The fresh and dried fruits were evaluated; the blackberry seedless pulp was used. The AA and flavonoids showed degradation of $70 \%$ and $20 \%$ compared to the fresh sample. For both compounds, SGD is the one that offers the greatest conservation.
\end{abstract}

Keywords: solar drying; antioxidant capacity; flavonoids; blackberry pulp (rubus spp); solar energy 


\section{Introduction}

México was the leader in the production of blackberry in recent years, with 248 thousand 500 tons per year and 13 thousand hectares had been planted for the year 2016 and $96 \%$ of the total production corresponds to the state of Michoacán [1,2]. Generally, the largest consumption of blackberries is fresh, but they can be processed and sold in different presentations such as: frozen in bulk or in individual containers, with or without seeds, lyophilized or in juices, in dietary supplements, jelly and jams [3].

The consumption of blackberry has received considerable commercial attention due to its content of phenolic compounds that contribute to its high antioxidant capacity whose health benefits have been well described [3]. Flavonoids have a wide range of biological effects, including antioxidant, anti-inflammatory, antiallergic, anti-ulcer, antibiotic and anticancer properties $[3,4]$. However, the blackberry is one of the most sensitive and perishable fruit products that exist. It is estimated that $50 \%$ of blackberry production is wasted from production to the end of the value chain (both cold and fresh), due to causes associated with the sensitivity of fruits and lack of conservation methods [5].

Solar dehydration technology offers an alternative for food preservation that is economical, needs low maintenance, environmentally friendly and preserves nutrients [6]. The objective of this study was to perform the solar dehydration of the blackberry pulp without seed and in form of a film with a thickness of $0.5 \mathrm{~mm}$, determining the characteristics of the drying using a greenhouse solar dryer and a direct solar dryer. The direct solar dryer was with natural convection and the greenhouse solar dryer with forced convection at $0.5 \mathrm{~ms}^{-1}$ (equipped with three solar air heaters). Additionally, the antioxidant capacity and the flavonoid content were determined as a measure of the quality deterioration of the product.

\section{Materials and Methods}

\subsection{Samples and pretreatment}

The samples of fresh blackberry were supplied by a local farmers from Los Reyes Michoacán Valley, the samples were considered "production process", that is, they did not meet export standards. They were frozen and transported to the Renewable Energy Institute, in Temixco Morelos where the tests were carried out. Before carrying out the drying tests, the blackberries were disinfected, pureed in a blender and the seeds were separated from the pulp with a strainer. They were placed in plastic trays of $33 \times 47 \times 1 \mathrm{~cm}$, the pulp formed a homogeneous film with thickness $0.5 \pm 0.1 \mathrm{~cm}$ and then dehydrated by each of the following methods.

\subsection{Drying methods}


The experimental study was carried out in Temixco, Morelos with a latitude of $18^{\circ} 50^{\prime} \mathrm{N}$ and a length of $99^{\circ} 14^{\prime} \mathrm{W}$ situated at elevation 1299 meters above sea level. The tests were carried out on July 16-17 (first drying), June 21-22 (second drying) and July 5-6 (third drying), of 2017. The samples were dehydrated between 9:30 am and 5:00 pm (solar time) continuously. The DSD and SGD prototypes are described in López, V. et al, [7] and Tamayo [8] and developed in the Renewable Energy Institute, (IER-UNAM).

\subsubsection{Direct Solar Drying (DSD).}

Two trays with blackberry pulp were placed in the direct dryer prototype (Fig. 1a), with an area of $0.48 \mathrm{~m}^{2}$ and exposed to direct sunlight until reaching a water loss equilibrium measured with a balace with an accuracy of $0.1 \mathrm{~g}$. The monitoring of the moisture loss of the product during drying was carried out by successive records every 20 minutes (first two hours of drying) and then every 30 minutes (up to constant weight).

\subsubsection{Solar Greenhouse Drying (SGD).}

Twenty six trays were placed with blackberry pulp (thirteen in each table) extended all along the table (Fig. 1b), inside the drying chamber of the greenhouse which operated with auxiliary solar heating up to constant weight. The recording and monitoring of weight loss was performed in the same way as that described for DSD.

\subsubsection{Electric Stove (ES).}

Two trays with blackberry pulp were placed inside the electric stove drying chamber at $60 \pm 1{ }^{\circ} \mathrm{C}$ with forced convection at $1 \mathrm{~ms}^{-1}$ for seven hours (time required to reach a constant weight loss). The recording and monitoring of weight loss was performed in the same way as that described for DSD and SGD.

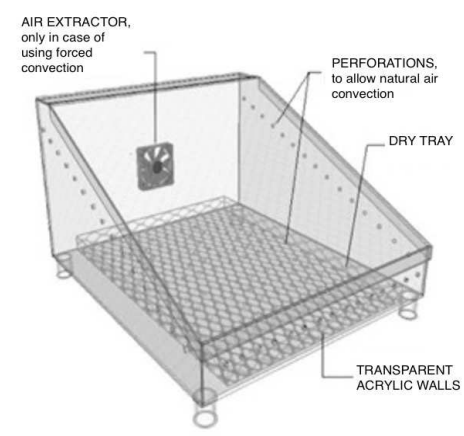

a)

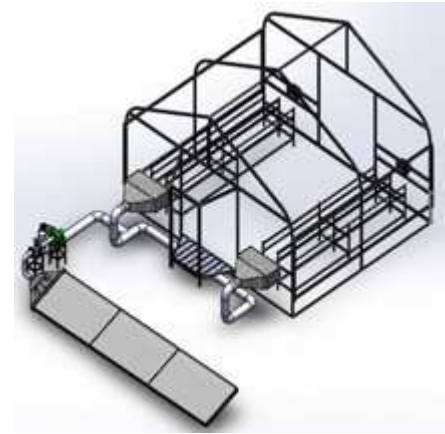

b)

Fig. 1a. Direct Solar Drying (DSD) scheme; 1b. Solar Greenhouse Drying (SGD).

\subsection{Extraction of organic compounds}


It was weighed $0.5 \mathrm{~g}$ of fresh and dried sample of blackberry pulp. Two secuencial extractions of organic compounds was carry out usin $5 \mathrm{ml}$ of methanol at $80 \%$, sonicated in an ultrasound bath for $30 \mathrm{~min}$, centrifuged at $1820 \mathrm{rpm}$ for $10 \mathrm{~min}$. The supernatant was recovered. The total organic extract was filtered with a Pasteur pipette packed and stored in an amber vial at $4^{\circ} \mathrm{C}$ until analysis.

\subsection{Antioxidant activity (AA)}

It was used the method developed by Blois, 1958 [9] and described by Brand-Williams et al. in 1995 [10] to determine antioxidant activity by the use of a stable free radical 1,1diphenyl-2-picrylhydrazyl (DPPH). In total darkness is added $100 \mu \mathrm{L}$ of the organic extract to a spectrophotometric cell followed by $2.9 \mathrm{ml}$ of DPPH reagent. After reaction for $30 \mathrm{~min}$ at $25{ }^{\circ} \mathrm{C}$ the absorbance versus prepared blank was read at $517 \mathrm{~nm}$. The results of antioxidant activity of the blackberry pulp (fresh and dried) were expressed as mg of equivalent ascorbic acid per gram of dry matter (mg AAE/g d.m) through the calibration curve with ascorbic acid (all samples were performed in triplicates). The calibration curve range was $0,5,9,12.5,17,21$ and $25 \mathrm{mg} / 100 \mathrm{ml}\left(\mathrm{R}^{2}=0.98\right)$.

\subsection{Total Flavonoid}

The total flavonoid content was determined by the aluminum chloride colorimetric assay $[11,12]$. An aliquot $(1 \mathrm{ml})$ of extracts or standard solution of quercentine was added to 10 $\mathrm{ml}$ amber vial containing $4 \mathrm{ml}$ distilled water and vortexed for 30 seconds. Was added 300 $\mu 1 \mathrm{NaNO}_{2}$ at $5 \%$, vortexed for 30 seconds, and incubate at room temperature for 6 minutes. After the time, $300 \mu \mathrm{l}$ of $\mathrm{AlCl}_{3}$ at $10 \%$ was added and keep it for 5 minutes at room temperature. Subsequently, $2 \mathrm{ml}$ of $\mathrm{NaOH}(1 \mathrm{M})$ was added, and finally the volume of each dilution was completed with $2.4 \mathrm{ml}$ of distilled water. The absorbance versus prepared blank was read at $510 \mathrm{~nm}$ after $30 \mathrm{~min}$ of reaction at $25{ }^{\circ} \mathrm{C}$. The results of total flavonoid content of the blackberry pulp (three replicates per treatment) are expressed as $\mathrm{mg}$ of equivalent quercetin per gram of dry matter (mg QE/g d.m). The calibration curve range was $20,40,60,80$ and $100 \mathrm{mg} / \mathrm{l}\left(\mathrm{R}^{2}=0.99\right)$.

\section{Results and discussion}

\subsection{Comparison of drying kinetics}

Fig. 2 shows the relationship of the average drying time $(n=3)$ and the final moisture content (less than $32 \%$ dry matter) by the different drying methods of the blackberry pulp. The reference of the kinetics is given by drying in electric stove (ES) were the drying time was $480 \mathrm{~min}$ at $60^{\circ} \mathrm{C}$ and $1 \mathrm{~ms}^{-1}$, the final moisture content was $0.31 \mathrm{~kg}$ of water per kilogram of dry matter. The DSD tests are carried out by natural convection and the SGD with forced convection at $0.5 \mathrm{~ms}^{-}{ }^{1}$. The average drying times for SGD and DSD 
corresponded to 960 min respectively, with a moisture content of 0.33 and $0.35 \mathrm{~kg} / \mathrm{kg}_{\mathrm{dm}}$. The drying times for solar technologies do not show significant differences.

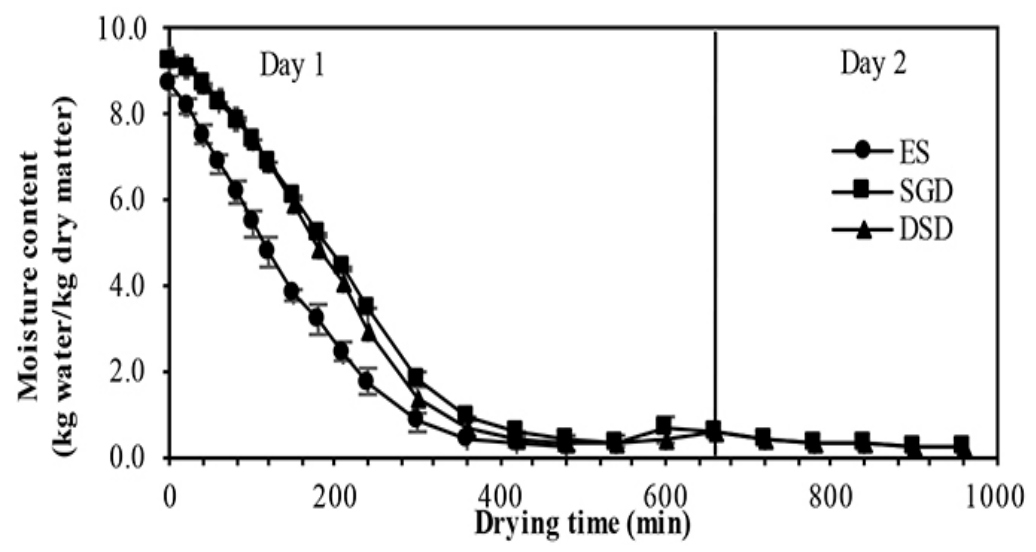

Fig. 2 Comparison of drying kinetics ( $n=3)$ by different methods: Solar Greenhouse Drying (SGD), Direct Solar Drying (DSD) and reference in electric stove (ES).

\subsection{Antioxidant Activity in blackberry pulp}

In Fig. 3 the antioxidant activity in the blackberry pulp of the fresh and dehydrated samples by the different technologies are presented. The fresh sample contains $20.22 \pm 2.94 \mathrm{mg}$ AAE/g d.m, and on average dehydrated samples loss $70 \%$ of their antioxidant capacity compared to fresh samples. The antioxidant activity in the blackberry dehydrated by SGD and DSD (5.86 \pm 0.51 and $5.80 \pm 0.39 \mathrm{mg} \mathrm{AAE} / \mathrm{g} \mathrm{d} . \mathrm{m})$ is barely greater than the method of drying in the electric stove $\mathrm{SE}(5.28 \pm 0.32 \mathrm{mg} \mathrm{AAE} / \mathrm{g} \mathrm{d} . \mathrm{m})$.

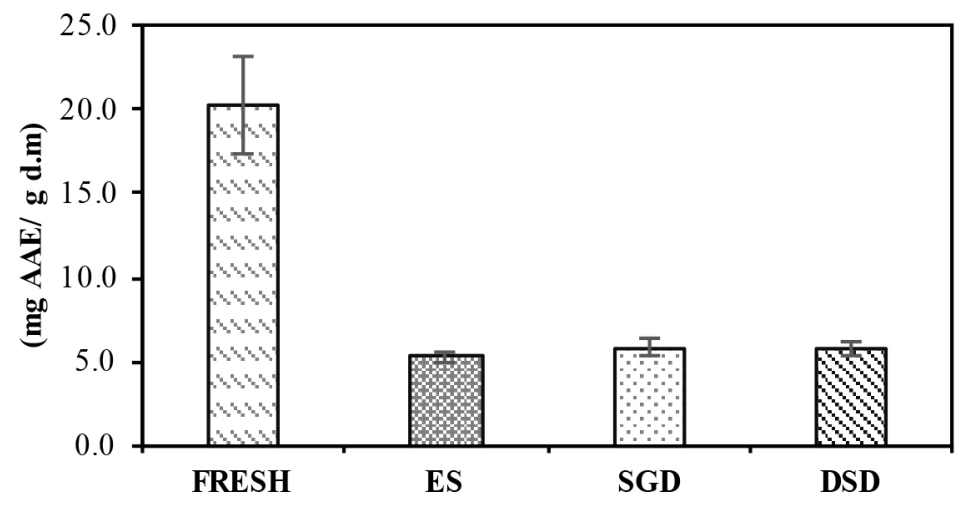

Fig. 3 Antioxidant activity of the blackberry pulp, fresh and dehydrated by different technologies

The concentration of the antioxidant activity is shown in Fig.4a for each of the three tests and for ecah drying technologies. The influence of the average irradiance of the day on the total antioxidant capacity of the samples is shown. For SGD and DSD samples 1 and 3 are 
affected by the influence of irradiance, with an inversely proportional correlation, a higher irradiance lower antioxidant activity, a lower irradiance greater antioxidant activity. However, sample 2 of SGD and DSD, seems not to follow this trend.

The Fig. $4 \mathrm{~b}$ shows the influence of temperature on antioxidant activity, for each of the tests dried by different technologies. The effect is shown by the influence of temperature giving an inversely proportional correlation. That is, the samples subjected to a higher average drying temperature correspond to the lower concentrations of the antioxidant activity. The samples dehydrated in the electric stove at $60{ }^{\circ} \mathrm{C}$, are those that have a lower antioxidant activity.

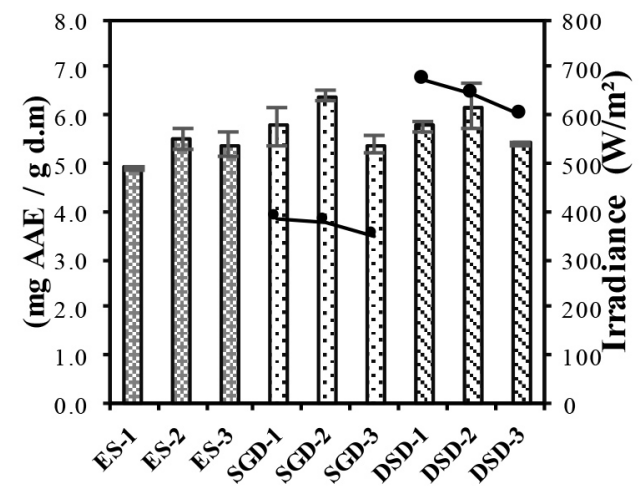

a)

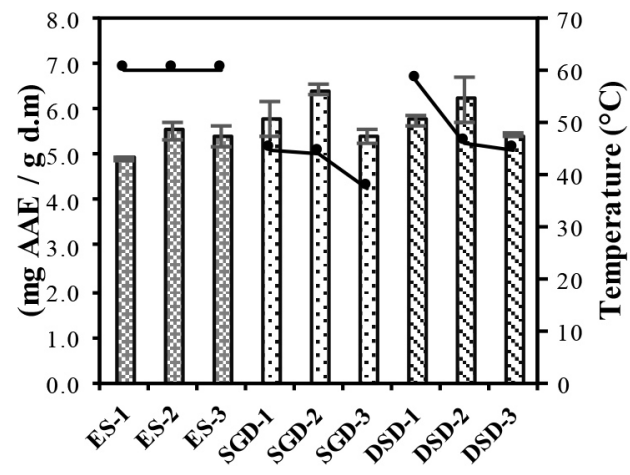

b)

Fig. 4a Antioxidant activity in blackberry pulp and its effect by irradiance; $4 \mathrm{~b}$ antioxidant activity in blackberry pulp and its effect by temperature.

\subsection{Total flavonoid content in blackberry pulp}

Fig.5 shows the content of total flavonoids in the blackberry pulp of the fresh and dehydrated sample. The fresh sample contains $12.17 \pm 0.79 \mathrm{mg}$ of $\mathrm{QE} / \mathrm{g} \mathrm{d}$.m. The samples dehydrated by SGD, DSD and ES technologies contain 10.53 $\pm 0.46,9.94 \pm 0.21$ and $8.89 \pm 0.24 \mathrm{mg}$ of QE/g d.m. On average the total flavonoids in dehydrated samples are degraded $20 \%$ compared to fresh samples.

Fig.6a shows the influence of average irradiance on the total flavonoid content. A correlation of the concentrations was observed for the samples that subjected it to a higher average irradiance, resulting in lower concentration of total flavonoids. In the same way, Fig. $6 \mathrm{~b}$ shows the influence of the average temperature of the day on the concentration of total flavonoids present. A greater effect due to the temperature is observed, since the samples dehydrated in the electric stove at $60^{\circ} \mathrm{C}$, are those that have a lower concentration, even when they are in darkness inside the drying chamber. Inside the drying chambers of SGD and DSD the samples that were subjected to a higher average temperature are those that show lower concentration of flavonoids, and vice versa. 


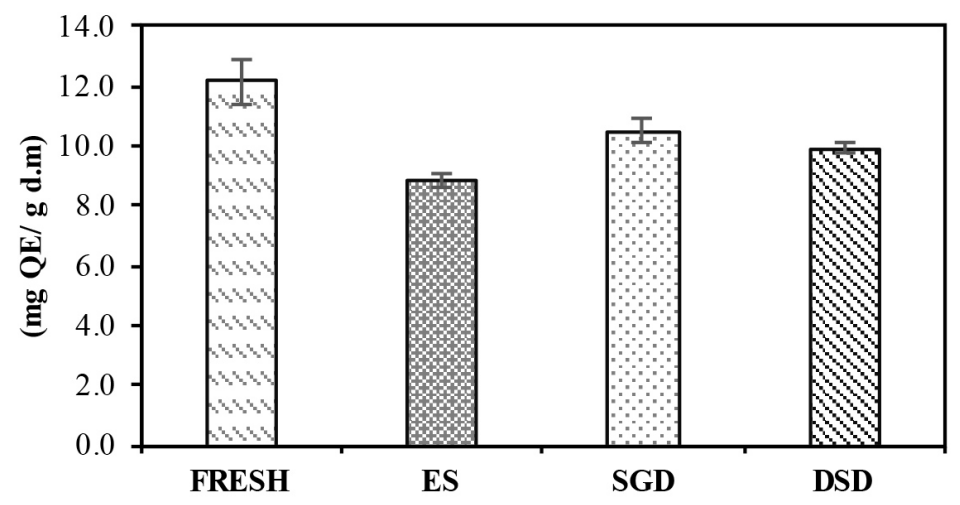

Fig. 5 Total flavonoids in the blackberry pulp, fresh and dehydrated by different technologies

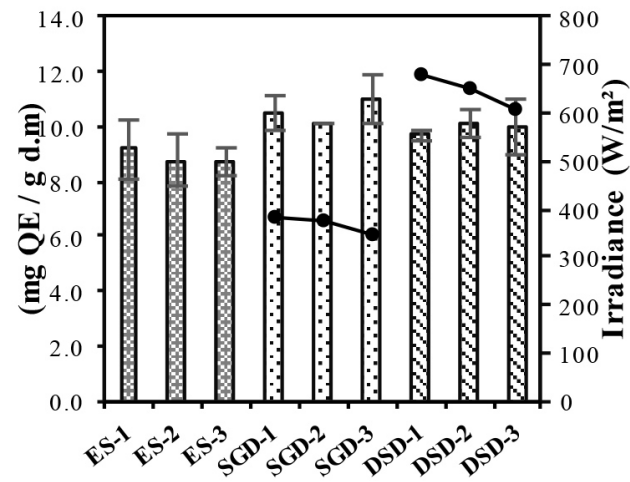

a)

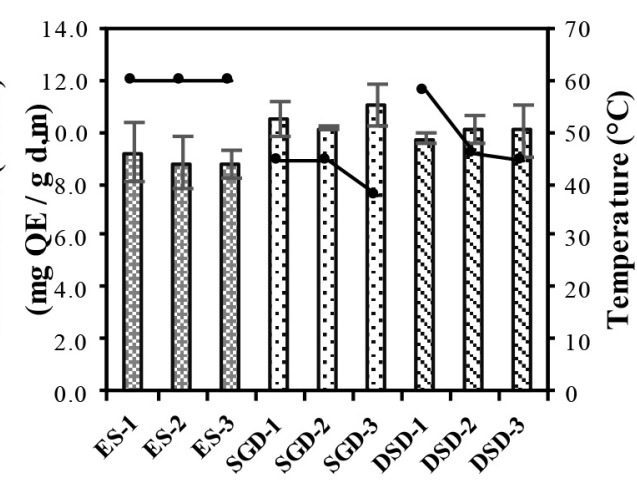

b)

Fig. 6a Total flavonoids in blackberry pulp and its effect by irradiance; 6 b total flavonoids in blackberry pulp and its effect by temperature.

\section{Conclusions}

The samples dehydrated by ES showed an average drying time of 480 min with a final moisture content $0.26 \mathrm{kgw} / \mathrm{kgdm}$. The samples dehydrated by solar technologies do not present significant differences between them, for SGD and DSD the average drying time was $960 \mathrm{~min}$, with final moisture content 0.33 and $0.35 \mathrm{kgw} / \mathrm{kgdm}$.. The antioxidant activity of dehydrated blackberry pulp by different technologies (SGD $5.86 \pm 0.51$, DSD $5.80 \pm 0.39$ and $5.28 \pm 0.32 \mathrm{mg}$ AAE / $\mathrm{gdm}$ ) show a decrease of $70 \%$ compared to fresh samples $(20.22 \pm 2.94 \mathrm{mg}$ AAE / gdm). The concentrations of total flavonides in fresh samples corresponding to $12.17 \pm 0.79 \mathrm{mg}$ of QE / gdm, and the concentrations measured in the dehydrated samples (SGD $10.53 \pm 0.46$, DSD $9.94 \pm 0.21,8.89 \pm 0.24 \mathrm{mg}$ of QE / 
gdm) represent a $20 \%$ decrease. In the comparison of solar technologies and electric stove, both solar technologies present a better conservation of flavonoid and antioxidant capacity. In the individual analysis of the tests a relation of temperature and irradiance in the final concentrations was observed, at higher temperature and irradiance, lower concentration of total flavonides and lower antioxidant capacity, having a greater effect on the drying temperature, since the dehydrated samples in the stove at $60^{\circ} \mathrm{C}$ shows the lowest concentrations.

\section{References}

[1] SIAP. Sistema de Información Agroalimentaria y Pesquera. Statistical Yearbook of Agricultural Production. 2017. Available: http://nube.siap.gob.mx/cierre_agricola/. [Access:17 September 2017].

[2] Food and Agriculture Organization of the United Nations. FAOSTAT. Available: http://www.fao.org/faostat/. [Access: 15 Febraury 2018].

[3] Kaume, L.; Howard, L. R. and Devareddy, L. The Blackberry Fruit: A Review on Its Composition and Chemistry, Metabolism and Bioavailability, and Health Benefits. J. Agric. Food Chem., 2012, 60 (23) 5716-5727.

[4] Cho, M. J.; Howard, L. R.; Prior, R. L. and Clark, J. R. Flavonoid glycosides and antioxidant capacityof various blackberry, blueberry and red grapegenotypes determined by high-performanceliquid chromatography/mass spectrometry. J. Sci. Food Agric. 2004, 84 (13) 1771-1782.

[5] Sáchez, R. G. La Red de Valor de la Zarzamora. El cluster de Los Reyes, Michoacán un ejemplo de reconversión competitiva. Morelia, 2008.

[6] Orsata, V.; Raghavana, G. S. V. and Soslea, V. Adapting Drying Technologies for Agri-Food Market Development in India. Drying Technol., 2008, 26 (11) 1355 1361.

[7] López, V. E., Pilatowsky, F.I and Navarro, O. Drying of Strawberry in a Direct and Indirect Solar Dryer (Effects of Drying Methods on Total Phenolic Content). IJAAEE, 2015, 2 (2) 61-63, 2015.

[8] Tamayo, H. D. Diseño, construcción, intrumentación y evaluación de un secador solar tipo invernadero. México, 2017.

[9] Blois, M. S.. Antioxidant Determinations by the Use of a Stable Free Radical. Nature, 1958, 181, 1199 - 1200 .

[10] Brand, W. W.; Cuvelier, M. and Berset, C. Use of a free radical method to evaluate antioxidant activity. LWT-Food Sci. Technol., 1995, 28 (1) 25-30.

[11] Mabry, T.; Markham, K. R. and Thomas, M. B. The systematic identification of flavonoids, Nueva York: Springer, 1970, p. 354.

[12] Zhishen, J.; Mengcheng, T. and Jianming, W. The determination of flavonoid contents in mulberry and their scavenging effects on superoxide radicals. Food Chem., 1999, 64, (4) 555-559, 1999. 